\title{
CLASSICAL AND NEOCLASSICAL INDETERMINACY IN ONE-SHOT VERSUS ONGOING EQUILIBRIA
}

\author{
Michael Mandler \\ Royal Holloway College, University of London
}

\begin{abstract}
I analyze two connections between neoclassical and classical economics. First, I consider the indeterminacy that arises for both schools: in the neoclassical theories of overlapping generations and of factor pricing and in Sraffa's price theory. Neoclassical indeterminacy occurs only in environments where relative prices can change through time; otherwise, determinacy obtains. Although these results challenge the Sraffian position on indeterminacy, the classical principle that current economic activity is embedded in the past proves to be a powerful insight: it establishes the robustness of factor-price indeterminacy and casts doubt on the importance of overlapping-generations indeterminacy. Second, I argue that recent claims that capital-theoretic paradoxes arise in intertemporal general equilibrium modes, not just in aggregative theory, cannot be validated.
\end{abstract}

\section{INTRODUCTION ${ }^{1}$}

What more could be said about Sraffa? For decades, both Sraffian critics and the neoclassical mainstream have held to fixed postions. The first camp claims that Sraffa's Production of Commodities by Means of Commodities (1960) showed that diverse capital goods cannot be fused into a one-dimensional aggregate. Factor prices therefore cannot be determined either as the marginal products of an economy-wide production function or, since Sraffians also assert that the equilibration of markets in neoclassical economics ultimately depends on the aggregation of capital, by supply and demand alone. Neoclassical economists should therefore acknowledge that purely economic forces leave the distribution

\footnotetext{
${ }^{1}$ I am grateful for the comments of Ana Fostel and Heinz Kurz, and for two incisive referee reports.
}

(C) Blackwell Publishers Ltd 2002, 108 Cowley Road, Oxford OX4 1JF, UK and 350 Main Street, Malden, MA 02148, USA. 
of income indeterminate. Supply and demand is not enough; power and politics must come into play. The neoclassical camp has replied that Arrow-Debreu general equilibrium theory long ago showed that neoclassical economics survives quite nicely without any aggregation-whether of capital, labour or output. Under weak conditions, the Arrow-Debreu model has at least one equilibrium and equilibria typically are determinate or locally unique. These results hold even for intertemporal models with linear production activities, the very setting of Sraffa's work. Neoclassical economists complain that Sraffians have ignored these developments and continue to press the impossibility of capital aggregation, on which no theoretical issue depends.

This synopsis is a caricature, of course. The general equilibrium response to Sraffa has not gone unanswered: one frequent rebuttal is to charge that intertemporal general equilibrium theory only does without the aggregation of capital by abandoning the traditional goals of the theory of value (see, for example, Garegnani (1976)). Prior to the Arrow-Dereu revolution, it is said, economists felt that they should explain the long-run relative prices towards which short-run market prices will gravitate. But in the modern-day general equilibrium theory, prices can take virtually any path and need not converge to any fixed point, no matter how much time passes.

But the picture of different camps sticking to well-entrenched positions is not a complete distortion. The Sraffian accusation that general equilibrium thoery fails to explain long-run prices has provoked little neoclassical response. To current-day neoclassicals, tying equilibrium theory to models in which relative prices stay constant through time hardly seems desirable. Does not the erratic character of technology and tastes make the flexibility of current-day general equilibrium models an advantage? And are not some natural resources becoming ever more scarce, thus preventing convergence to any constant-relativeprice long run? Moreover, there are neoclassical models of the long run, of both the overlapping-generations and finite-agent infinite-horizon variety, in which relative prices do stabilize through time. Sraffians have not embraced these neoclassical accounts of the long run, principally on the grounds that in these models relative prices stabilize only in the same lengthy time frame that capital stocks approach steady-state levels. I suspect, however, that in calibrated overlapping-generations models with multiple capital goods, relative prices would approximately converge to long-run values comparatively swiftly-and well prior to the point at which capital goods reached steady-state levels. If so, then there would be a neoclassical theory in which long-run relative prices

(C) Blackwell Publishers Ltd 2002 
serve as a 'centre of gravity' towards which short-run prices quickly return.

The Sraffa-neoclassical debate terminated long ago as a two-sided argument, and the Sraffian championing of models with constant relative prices is so distant from contemporary neoclassical concerns that I doubt the debate is on the verge of revival. Leaving politics aside, the pitched battles of the past were fuelled by the joint recognition that Sraffian capital theory had identified genuine defects in the neoclassical synthesis of the 1960s. Today the neoclassical side sees no serious capital-theoretic difficulties outstanding.

Still, each side of the neoclassical-Sraffa divide has something to learn from the other. I consider two topics. First, indeterminacy of equilibrium is not solely owned Sraffian territory. The claim that supply and demand can leave the distribution of income indeterminate finds close parallels in factor-price indeterminacy and in the overlapping-generations model. These neoclassical literatures, however, consistently come to one stubbornly anti-Sraffian conclusion: indeterminacy appears outside of steady states but not in the long-run models favoured by Sraffian theory. Nevertheless, one of Sraffa's key insights - seeing equilibrium as ongoing and embedded in time and not as a one-shot match of supply and demand-reveals when neoclassical indeterminacy occurs and how it should be interpreted. Neoclassical economists instinctively adopt the one-shot point of view and rarely appreciate when results hinge on this method. Second, the long-held Sraffian view that intertemporal general equilibrium theory, although coherent on its own terms, must be rejected out of court has moderated a bit. In the recent collection edited by Heinz Kurz, Critical Essays on Piero Sraffa's Legacy in Economics (2000), Bertram Schefold and Pierangelo Garegnani argue in separate essays that the Sraffian critique of neoclassical capital theory applies just as much to general equilibrium as to aggregative models. This work attempts to bridge the long-standing gulf beween the Sraffian and general equilibrium camps, and deserves serious comment. I will conclude with some suggestions about how the Sraffa agenda would be best pursued today.

My focus on the Schefold and Garegnani essays reflects their pertinence to the Sraffa-general equilibrium debate. The Kurz volume contains several other pieces of interest; let me recommend Kurz's own essay on the Hayek-Sraffa debate of the 1930s and Mainwaring and Steedman's piece on the probability (rather than the in-principle possibility) of reswitching.

C) Blackwell Publishers Ltd 2002 


\section{NEOCLASSICAL VERSUS SRAFFIAN INDETERMINACY}

Indeterminacy arises in many places in neoclassical economics, but overlapping-generations indeterminacy and factor-price indeterminacy have particularly interesting connections to Sraffa.

\subsection{Factor-price indeterminacy}

Suppose three factors that agents supply inelastically can be used only in the production of two outputs, $\delta$ and $\varepsilon$. The outputs are produced by the linear activities $\left(\delta_{1}, \delta_{2}, \delta_{3}\right)$ and $\left(\varepsilon_{1}, \varepsilon_{2}, \varepsilon_{3}\right)$, where the coordinates indicate the amounts of the three factors necessary to produce one unit of $\delta$ and $\varepsilon$ respectively. Letting $w=\left(w_{1}, w_{2}, w_{3}\right)$ denote factor prices and $p=\left(p_{\delta}, p_{\varepsilon}\right)$ the output prices, the conditions

$$
\begin{aligned}
& w_{1} \delta_{1}+w_{2} \delta_{2}+w_{3} \delta_{3}=p_{\delta} \\
& w_{1} \varepsilon_{1}+w_{2} \varepsilon_{2}+w_{3} \varepsilon_{3}=p_{\varepsilon}
\end{aligned}
$$

ensure that the activities make zero economic profits. The $p$ s can be discounted or present-value prices, so (2.1) is consistent with production taking time and invested capital earning the rate of interest.

To model the quantity relationships, let $\left(e_{1}, e_{2}, e_{3}\right)$ denote the endowments of the inelastically supplied factors. The production levels of $\delta$ and $\varepsilon$, say $\left(y_{\delta}, y_{\varepsilon}\right)$, must satisfy the inequalities

$$
\begin{aligned}
& y_{\delta} \delta_{1}+y_{\varepsilon} \varepsilon_{1} \leqslant e_{1} \\
& y_{\delta} \delta_{2}+y_{\varepsilon} \varepsilon_{2} \leqslant e_{2} \\
& y_{\delta} \delta_{3}+y_{\varepsilon} \varepsilon_{3} \leqslant e_{3}
\end{aligned}
$$

When any of these inequalities is slack, the corresponding factor price must equal 0 .

We assume for now that there is a $\left(\bar{y}_{\delta}, \bar{y}_{\varepsilon}\right)$ that satisfies each inequality in (2.2) with exact equality, i.e. each factor is fully employed. If the $e$ s were chosen randomly, this would be an unlikely occurrence: three equations in the two variables will generally have no solution. (Think of three lines on a two-dimensional plane: usually, they will have no point of common intersection.) But, as we discuss in more detail in section 3, past investment decisions ensure that the endowments of some factorsthe capital goods-appear in particular configurations. Investors will not

(C) Blackwell Publishers Ltd 2002 
so overproduce a capital good that it comes to be in excess supply and hence free.

To see how factor-price indeterminacy arises in partial equilibrium, suppose temporarily that the demand for $\delta$ and $\varepsilon$ is a function of $p$ only, and let us fix prices at a $\bar{p} \gg 0$ such that demand for $\delta$ and $\varepsilon$ equals $\left(\bar{y}_{\delta}, \bar{y}_{\varepsilon}\right)$; if there were an aggregate agent, $\bar{p}$ would be proportional to the agent's marginal utilities when consuming the bundle $\left(\bar{y}_{\delta}, \bar{y}_{\varepsilon}\right)$. The market-clearing requirements for the factors, (2.2), and for $\delta$ and $\varepsilon$ are thus all satisifed at $\bar{p}$. The only remaining equilibrium condition is (2.1), which contains two equations in the three factor prices. So if there is some $\bar{w} \gg 0$ satisfying (2.1), there must be a continuum of solutions-a dimension of indeterminacy. The assumption that factors are supplied inelastically is key. Otherwise variations in the $w$ would induce changes in the factor supplies $e$, and then it would be unlikely that (2.2) could continue to hold with equality, since, as mentioned, (2.2) will not be satisfied with equality for most values of $e$. Moreover, when one or more inequalities in (2.2) holds as a strict inequality, one or more factors will be in excess supply and their prices must equal zero, thus eliminating an endogenous variable and hence the indeterminacy. ${ }^{2}$

The model so far does not establish general equilibrium indeterminacy since when the demand for $\delta$ or $\varepsilon$ is a function of $w$, variations in $w$ might well be inconsistent with the output markets clearing at the production levels $\left(\bar{y}_{\delta}, \bar{y}_{\varepsilon}\right)$. To fix this problem, add explicit marketclearing conditions for $\delta$ and $\varepsilon$,

$$
\begin{aligned}
& x_{\delta}(p, w)=y_{\delta} \\
& x_{\varepsilon}(p, w)=y_{\varepsilon}
\end{aligned}
$$

where $x_{\delta}(p, w)$ and $x_{\varepsilon}(p, w)$ are the demand functions for $\delta$ and $\varepsilon$. For simplicity only, we have stated (2.3) (and (2.1) earlier) as equalities rather than inequalities. We assume that Walras's law,

$$
p_{\delta} x_{\delta}(p, w)+p_{\varepsilon} x_{\varepsilon}(p, w)=w_{1} e_{1}+w_{2} e_{2}+w_{3} e_{3}
$$

is satisifed at any $(p, w)$.

Once again, for indeterminacy to obtain the three original factors must be fully employed in equilibrium: no inequality in (2.2) can be slack.

\footnotetext{
2 The earliest formal presentation of the factor-price indeterminacy that can accompany linear activities is Stackelberg (1933). See Mandler (1999a, ch. 2) for mathematical and historical details.
} 
Let $\left(\bar{p}, \bar{w}, \bar{y}_{\delta}, \bar{y}_{\varepsilon}\right)$ denote such an equilibrium and again fix the production levels $\bar{y}_{\delta}$ and $\bar{y}_{\varepsilon}$. Condition (2.2) is then satisfied at all values of $p$ and $w$, and so only three independent equations remain (we lose one equation due to Walras's law) to determine the four relative prices in $p$ and $w$. Hence one dimension of indeterminacy again appears. In comparison to the partial-equilibrium indeterminacy argument based solely on equation (2.1), the present argument treats two more variables, the output prices, as endogenous, but this is counter balanced by the two market-clearing conditions for output (and as usual the fact that we only need to determine relative prices is offset by Walras's law).

No essential change occurs if additional goods or activities are present as long as the three original factors are not used in equilibrium by any of the added activities. For example, with $\ell$ extra goods with a non-zero price and $n$ extra activities in use in equilibrium (and with conditions (2.1)-(2.3) remaining in place), the model would gain $n$ new production levels and $\ell$ new prices as endogenous variables but also gain $n+\ell$ additional equilibrium equations, $n$ zero-profit conditions and $\ell$ marketclearing conditions. Hence, fixing $\bar{y}_{\delta}$ and $\bar{y}_{\varepsilon}$ again leaves a surplus of endogenous variables over equilibrium conditions.

In addition to inelastic factor supply, three conditions drive the indeterminacy.

First, production must be described by activities rather than differentiable production functions. The indeterminacy reasoning above finds multiple factor prices that support a single set of quantities produced and factors utilized. But if marginal products were everywhere well defined, fixed quantities would be compatible with only one set of factor prices (Mandler (1997)). (Arbitrary finite sets of activities, on the other hand, are consistent with indeterminacy.) This link between indeterminacy and linear activities fits well with the Sraffian tradition. Sraffa implicitly questioned how an aggregate differentiable production function could be built from linear activity foundations. Factor-price indeterminacy does not address aggregation per se, but it shows exactly where the logic of defining marginal products breaks down when general equilibrium models take activities rather than differentiable production functions as the description of production.

Second, granting the use of activities, indeterminacy requires that some set of $m$ scarce factors is used by fewer than $m$ activities. (In the example, we let $m$ equal 3 and the number of activities equal 2, generating a single degree of indeterminacy, but if the gap between the number of factors and the number of activities using those factors were larger, the dimension of indeterminacy would grow accordingly.) Hence,

(C) Blackwell Publishers Ltd 2002 
for factor-price indeterminacy to obtain, some set of $m$ market-clearing conditions (analogous to (2.2)) must hold with equality and those $m$ equalities will contain fewer than $m$ endogenous variables (the production or activity levels). So it might seem that factor-price indeterminacy will always be an unlikely event. As we shall see in section 3, the situation is not so simple.

Third, if equilibria are required to exhibit constant relative prices through time, as in Sraffa's Production of Commodities by Means of Commodities, then indeterminacy will not arise. Each factor in an economy is either produced or endowed by nature. In the produced case, the requirement that relative prices stay constant constrains the relative price of the existing stock of a factor at time $t$ to equal the relative price of the same factor appearing as an output at $t+1$. So an additional equilibrium condition is present. In the endowed-by-nature case, one can reasonably take factor endowments to be random. Hence, it will almost always be impossible to solve equilibrium conditions such as (2.2) in which a set of $m$ factors is fully employed by fewer than $m$ activities. Using one or both of these arguments, one may show that full determinacy typically obtains (the details are a bit complicated-see Mandler (1999b)). We shall see a similar contrast in the next section on overlapping-generations indeterminacy: some overlapping-generations equilibria can be indeterminate, but not the long-run equilibria.

\subsection{Overlapping-generations indeterminacy}

Consider a simple overlapping-generations model in which one generation is born at each date $t \geqslant 0$ and lives two periods. Two goods appear each period and we suppose for simplicity that there is no production and that agents are endowed with all four of the goods that appear in their lifetime. We also assume the primitives of the economy are stationary: each generation has the same number of agents and each agent in each generation has one exact replica (with the same utility function and endowments) in every other generation.

Agents choose consumption levels of the four goods that appear in their lifetime so as to maximize their utility; an agent's demand for goods is therefore determined by three relative prices. Set the price of good 1 in each period equal to 1 , and let $p_{t}$ denote the price of good 2 at each $t$. We may then think of the three relative prices that matter to the generation born at $t$ as $p_{t}, p_{t+1}$, and the interest rate $r_{t}$ earned from lending at $t$ for a return at $t+1$. Given our choice of numéraire,

Blackwell Publishers Ltd 2002 
borrowing and lending contracts are calculated in terms of good 1: $r_{t}$ is the good 1 'own' rate of interest. Using $\left(c_{1}(1), c_{1}(2)\right)$ and $\left(c_{2}(1), c_{2}(2)\right)$ to denote consumption when young and old, respectively, and $\left(e_{1}(1), e_{1}(2)\right)$ and $\left(e_{2}(1), e_{2}(2)\right)$ to denote endowments when young and old, respectively, an agent born at $t$ faces the budget constraints

$$
\begin{aligned}
& c_{1}(1)+p_{t} c_{1}(2)+s \leqslant e_{1}(1)+p_{t} e_{1}(2) \\
& c_{2}(1)+p_{t+1} c_{2}(2) \leqslant e_{2}(1)+p_{t+1} e_{2}(2)+s(1+r)
\end{aligned}
$$

where $s$ is the agent's quantity of saving (if positive) or borrowing (if negative). We could combine the two budget constraints together by substituting out the variable $s$, thus yielding the familiar intertemporal constraint that the present value of the agent's consumption cannot exceed the present value of the agent's endowment.

In the equilibria we consider, agents have perfect foresight. Hence, the good 2 rate of interest must be such that trading good 1 at $t$ for good 2, investing the proceeds at the good 2 rate of interest, and then trading back the return into good 1 at $t+1$ earns the good 1 rate of interest $r_{t}$. So the good 2 rate of interest is fully determined by $p_{t}, p_{t+1}$ and $r_{t}$.

Each agent maximizes utility subject to the above budget constraints. Aggregate demand for the two date- $t$ goods is the sum across agents of the demand for those goods. Of couse, only the agents who are alive at $t$ desire date- $t$ goods.

An equilibrium is a sequence $\left\{p_{t}, r_{t}\right\}_{t \geqslant 0}$ such that the demand for goods at each date $t$ equals the aggregate endowment. At each $t$, agents directly observe the price $p_{t}$ and the interest rate $r_{t}$ on borrowing or lending into $t+1$. In addition, the young at $t$ unanimously anticipate that $p_{t+1}$ will rule next period-this is the perfect foresight assumption. So, as the equilibrium proceeds through each date $t$, the equilibrium path will consist of two current prices and expectations of the remainder of the price sequence.

Why does indeterminacy arise in this model? Suppose we fix $p_{0}$ at some arbitrary level, and then hunt for an $\left(r_{0}, p_{1}\right)$ that generates an equilibrium of demand and supply for the date- 0 goods. If such values exist, search for an $\left(r_{1}, p_{2}\right)$ that clears the markets for date-1 goods and, at each subsequent $t$, search for an $\left(r_{t}, p_{t+1}\right)$ that clears the date- $t$ goods markets. Suppose we thereby discover a complete equilibrium sequence $\left\{\bar{p}_{t}, \bar{r}_{t}\right\}_{t \geqslant 0}$. The easiest case to analyse is where $\left(\bar{r}_{t}, \bar{p}_{t+1}\right)$ converges to some $(\bar{r}, \bar{p})$. Not surprisingly, it will generally be the case if we choose a $p_{0}$ close to $\bar{p}_{0}$ that there will be an $\left(r_{0}, p_{1}\right)$ that clears the goods

(C) Blackwell Publishers Ltd 2002 
markets at time 0 and that is close to $\left(\bar{r}_{0}, \bar{p}_{1}\right)$. It also turns out that the convergence of $\left(r_{t}, p_{t+1}\right)$ to $(\bar{r}, \bar{p})$ will frequently be robust: if $p_{0}$ is sufficiently near to $\bar{p}_{0}$ then $\left(r_{t}, p_{t+1}\right)$ will still converge to $(\bar{r}, \bar{p})$, where as before we construct the sequence of the $\left(r_{t}, p_{t+1}\right)$ to always clear markets at $t$. Indeterminacy therefore obtains: there is a continuum of equilibria, each differing in its precise convergence path to $(\bar{r}, \bar{p})$, and each of which we can identify with the arbitrary $p_{0}$ at the beginning of the path (see Kehoe and Levine (1985)).

Overlapping-generations indeterminacy necessarily involves an indeterminacy of expectations. If we fix the value of $p_{1}$ that agents anticipate at $t=0$, the values of $p_{0}$ and $r_{0}$ that will clear markets at $t=0$ will be locally unique (determinate). A continuum of equilibria arises only when agents' expectations of future prices change in tandem with current prices.

If we expand the number of goods per period, the maximal dimension of indeterminacy grows accordingly. With an extra good per period, each period $t$ will have one additional market-clearing condition but two new endogenous variables dated $t$ or later that can influence the demand for goods at $t$ : the price of the extra date- $t$ good and the price of the extra date- $t+1$ good. The additional good thus yields an extra degree of freedom and hence increases the potential dimension of indeterminacy by one. ${ }^{3}$

We have considered only overlapping-generations equilibria that converge to a single $(\bar{r}, \bar{p})$. The exact equilibrium paths of interest rates and relative prices differ, but in the end they approach the same $\bar{r}$ and $\bar{p}$. In the indeterminacy discussed by Sraffa in Production of Commodities by Means of Commodities, in contrast, the long-period rate of interest $\bar{r}$ itself varies. Recall that with $n$ industries, Sraffa's model imposes $n$ equations stipulating that each industry earns the same rate of interest (or profit) on capital invested. Since these $n$ equations cannot determine the $n+1$ endogenous price variables $(n-1$ relative goods prices, the interest rate $r$ and the wage rate), Sraffa concludes that a single dimension of indeterminacy is present.

It is not just that some instances of overlapping-generations indeterminacy involve equilibria that converge to the same $(r, p)$. In typical overlapping-generations models, all of the long-run equilibria are determinate. One can state this claim formally by defining a long-run

\footnotetext{
3 Overlapping-generations indeterminacy first appears in Gale (1973), although he does not identify it as such. Calvo (1978) is also an early source. See Kehoe and Levine (1985) for an accounting of the dimension of indeterminacy.
} 
equilibrium not as a point of convergence but as a sequence $\left\{p_{t}, r_{t}\right\}$ where $\left(p_{t}, r_{t}\right)$ equal some $(\bar{p}, \bar{r})$ for all $t$ and where $t$ now stretches into the infinite past as well as the infinite future. ${ }^{4}$ In contrast to the infinite chain of distinct interest rates and relative prices in the non-long-run case, a long-run equilibrium has just two endogenous variables, $\bar{r}$ and $\bar{p}$, and these are locally determined by the two conditions setting per-period demand for the two goods equal to supply. Only two conditions are pertinent since, with relative prices and interest rates constant through time, any one period's market-clearing conditions are identical to any other's. And the determinacy conclusion remains correct if there are more than two goods per period: for each additional good, one additional relative price appears but one additonal market-clearing condition also holds.

The determinacy of long-run equilibria may explain why the overlapping-generations model has drawn so little attention in the Sraffian literature. In the most studied cases, the infinity of different equilibria differ only in the exact path they take to reach the same determinate end point. But long-run determinacy nevertheless poses a challenge: if only long-run equilibria are of legitimate interest, is not the neoclassical theory of overlapping generations a complete and internally consistent theory of the long run that does without the aggregation of capital?

\section{ONE-SHOT VERSUS ONGOING EQUILIBRIA}

The central character of classical economics is the accumulating capitalist investing his previously amassed surplus in future production. The parallel figure in Walrasian theory is the individual agent whose endowments and preferences are determined in isolation from others, but who, like a nomad happening upon an oasis, finds that trade with others brings opportunities for gain. Correspondingly, the equilibria of classical models are embedded in the economic past and do not begin de novo each period, whereas neoclassical equilibria often start at an imagined beginning of economic time or with arbitrary primitives (preferences, endowments and technology) that are not determined by prior economic activity.

But the principle that equilibria are embedded in the past does not imply that relative prices will gravitate to fixed long-run values. If oil ${ }^{4}$ For proofs of generic long-run determinacy, see Kehoe and Levine (1984) for exchange
and Mandler (1999b) for production economies. 
becomes progressively more difficult to find or extract, the price of oil is likely to rise steadily, and goods whose production is relatively oil intensive will also become increasing expensive. This conclusion holds whether agents foresee that oil prices will rise, or if oil price changes come as a surprise. Fortunately, the classical method can be disentangled from its application to long-run prices. As we shall now see, understanding current prices as a particular stage of an ongoing equilibrium clarifies the meaning of indeterminacy in neoclassical economics: the classical perspective reveals how limited overlapping-generations indeterminacy is, but shows that factor-price indeterminacy is a systematic event.

Consider first an indeterminate equilibrium of the overlappinggenerations model. We could each period ignore the past history of trades and equilibrium prices and instead treat the current period as a fresh beginning. A one-dimensional set of equilibria would then reappear each period. But after the economy has been in operation for one or more periods, almost all of the equilibria in this set would violate the expectations that the current old generation formed in the previous period when they were young. In an equilibrium with perfect foresight, the agents born during period $t$ know the current and subsequent period's relative prices, $p_{t}$ and $p_{t+1}$, and the interest rate $r_{t}$ linking their youth and old age. If we were to require that current prices fulfil past expectations, then at each period $t+1$ the variable $p_{t+1}$ will be predetermined. But then the two market-clearing conditions for date- $t+1$ goods will fix the equilibrium values of $r_{t+1}$ and $p_{t+2}$. Proceeding onwards, the entire equilibrium sequence will be pinned down.

One might retort that bygones are bygones: agents have no recourse if supply and demand bring about an equilibrium that violates past expectations. But once an equilibrium path becomes established, the expectations that constitute part of the equilibrium will ensure that the path continues as anticipated. Along the equilibrium path, agents at period $t$ unanimously expect some sequence $\left\{p_{\tau}, r_{\tau}\right\}_{\tau>t}$. Given these expectations, the equilibrium prices for period $t, p_{t}$ and $r_{t}$, will be locally unique: they are determined by the two goods markets at period $t$. If, therefore, agents unanimously come to expect an equilibrium price path, then during each period the prices that clear current markets are locally unique and those determinate market-clearing prices will fulfil agents' previously formed expectations. These conclusions do not change if the model is subject to stochastic shocks. Goods are then interpreted as commodities contingent on the realization of past and present shocks.

Classical methodology therefore suggests that overlapping-generations

C Blackwell Publishers Ltd 2002 
indeterminacy does not provide a route for non-market forces (such as power and politics) to influence equilibrium. Except at the beginning of economic time, market forces perform the same determining role they do in finite-horizon Walrasian models.

How does the embedding of equilibria in time affect factor-price indeterminacy? We appealed already in section 2 to the importance of the past in claiming that not all factor endowment levels are equally plausible. When endowments are random-when, for example, they are determined by nature - the probability that some set of $m$ factors will be fully employed by fewer than $m$ activities is zero. One might therefore be tempted to dismiss such a possibility (as argued implicitly by Kehoe (1980) and Mas-Colell (1975, 1985)) and conclude that factor-price indeterminacy is exceedingly unlikely. But when factor endowments are set by an equilibrium process - as when the level of investment goods is chosen by agents so as to maximize their rate of return-the endowments consistent with indeterminacy appear systematically.

One way to model the equilibrium determination of factor endowments is to see an intertemporal economy as proceeding via a sequence of markets that meet at each period, rather than meeting once-and-for-all at the beginning of time. An overall intertemporal equilibrium, which in a two-period case stipulates prices for goods at dates 1 and 2 , then translates into a first-period equilibrium in which date-1 prices serve as current market prices and agents unanimously expect the date- 2 prices to be the market prices in the next period. I have shown elsewhere (Mandler (1995)) that the troublesome endowment points that generate indeterminacy can arise systematically in period 2. For instance, in the example in section 2, factor-price indeterminacy obtains only if (2.2) holds with equality, an event that rarely occurs if endowments are random. But when the accumulation of capital is in equilibrium, the economy's endowments evolve to ensure that capital goods are not in excess supply. So (2.2) can systematically hold with equality if one or more of the three factors is a produced capital good, and so a continuum of equilibria will emerge in period 2. It is not at all unusual, therefore, for factor-price indeterminacy to emerge along an equilibrium path.

Thus, unlike the case of overlapping-generations indeterminacy, the classical linkage of past and present creates an ideal setting for factorprice indeterminacy. But can one object, mimicking our earlier objection to overlappping-generations indeterminacy, that only one of the continuum of equilibria in period 2 will validate the expectations agents formed in period 1? While it is true that only one second-period equilibrium will confirm prior expectations, factor-price indeterminacy

(C) Blackwell Publishers Ltd 2002 
nevertheless dramatically influences agents' behaviour, even to the point of undermining the assumption that agents could be competitive pricetakers. The distinctiveness of factor-price indeterminacy is that current markets cannot pin down current prices (unlike overlapping-generations indeterminacy where, once expectations are fixed, current markets do determine current prices) and therefore factor owners will attempt to manipulate markets to their advantage. ${ }^{5}$ If, for example, two factors are used by only one activity and both factors are fully employed, then the slightest withdrawal of, say, factor 1 from the market will cause factor 2 to be in excess supply, sending its price to zero and increasing the price of factor 1 accordingly. In the face of such powerful incentives to manipulate markets, a competitive equilibrium would break down and non-market institutions to regulate trade would have to be created.

\section{NEW CRITICISMS OF INTERTEMPORAL GENERAL EQUILIBRIUM THEORY}

In separate pieces in Critical Essays, Bertram Schefold and Pierangelo Garegnani argue that the intertemporal general equilibrium model is subject to the same capital-theoretic difficulties that trouble the older aggregative models.

\subsection{Schefold}

Consider a simple case of reswitching involving two goods that are both consumed and used as capital inputs and a list of single-output linear activities that use both goods as inputs. Associated with each interest rate $r$ is a particular pair of activities and a price vector $p(r)$ such that, if $p(r)$ are the prices of both inputs and outputs, each activity in the pair earns the rate of return $r$ and no other activity can produce at lower cost. Set a numéraire by letting the price of good 1 equal one throughout. The capital-theoretic paradox lies in the possibility that one pair of

\footnotetext{
5 Even if more periods - a third and fourth say-were to follow the second period in the model of endogenous endowments, agents' expectations of prices in periods 3 and 4 and current (second-period) market-clearing conditions would not be able to pin down secondperiod prices. The reason is that the endowment points that cause indeterminacy can still arise in period 2, and hence the indeterminacy arguments of section 2.1 apply.
} 
activities, $\alpha$, can be profit-maximizing at low and high $r$ but another set, $\beta$, can be profit-maximizing at intermediate $r$ s.

Schefold builds a single-agent general equilibrium model to exhibit this case of reswitching. The economy starts out using the $\alpha$ activities, with a high interest rate, say $r_{H}$, and with prices $p\left(r_{H}\right)$ that are constant through time. At some point the economy experiences an increase in its inelastically supplied stock of labour and permanently switches to the $\beta$ activities. Meanwhile $r$ discretely and permanently shifts down to one of the intermediate interest rates mentioned above, say $r_{I}$. The subsequent path of prices is then fully determined by the requirement that the $\beta$ activities earn zero economic profits and it turns out that prices converge forward to $p\left(r_{I}\right)$. (The inflow of labour and the switch to the new interest rate need not occur simultaneously, but the path of interest rates and prices is perfectly anticipated.) There are many ways to complete the model so that equilibrium displays these properties. Schefold keeps the gross output of each good constant along the entire equilibrium path, and adusts the inputs of the two goods so that the larger labour supply is fully employed in each period. To ensure that the single agent consumes the residual quantity of output after inputs are subtracted, the agent is given an intertemporal utility function such that at those consumption levels the agent's marginal utility for each of the goods is proportional to the discounted value of the corresponding price on the price path specified above. (So intertemporal utility is not a discounted sum of an unvarying per-period utility function.) Since the economy converges to a lower $r$, the real wage (calculated in terms of either good) rises. Schefold declares this equilibrium to be implausible: a higher labour supply is associated with a higher real wage and one could hardly expect the market to drive wages higher in response to greater supply.

Schefold's decision to include just a single agent not only simplifies his model, it ensures that any comparative statics puzzle will be attributable to capital-theoretic issues, not the well-known perversities of multi-agent aggregate demand functions. Schefold's model nevertheless does not present a real paradox, since along with the increase in labour supply the model also shifts the agent's per-period utility function. So, for instance, the relative price of one of the two goods rises along Schefold's equilibrium path, but the agent's marginal utility for that good rises to match, even in parts of the path where consumption of both goods remains constant. Since, according to any neoclassical price theory, the direction of price changes can be arbitrary when both supply and demand shift, it is not obvious that Schefold's equilibrium is in any way implausible.

(C) Blackwell Publishers Ltd 2002 
To establish genuine paradox, one must show that an increase in labour supply alone will increase the wage above what it would have been absent the increase. For example, one might show that an economy with endowments and preferences that remain fixed through time, and that ex ante has constant relative prices and interest rates, would have higher wages relative to the same economy with a larger labour supply. But due to fact that Schelfold's economies have a single agent, changes in factor endowments will generate the accustomed neoclassical responses. Assuming the single agent has a concave utility function, a larger endowment of a factor will diminish that factor's direct or imputed marginal value relative to what its marginal value would have been without the increase. Compare two equilibria of Schefold's model, a base case and a perturbed model that differs only in that at date $\tau$ and after the economy's labour endowment increases by some fixed quantity per period. If the single agent's utility is concave as a function of the consumption levels, the 'derived' utility function that takes the economy's labour endowments as its arguments will also be concave. Hence, as the vector of labour endowments from date $\tau$ onwards goes up, the marginal utility of an increase in that endowment vector cannot be larger than the marginal utility of an increase in the base-case equilibrium. The single-agent assumption, which Schefold needs to isolate the effects of reswitching, is so strong that the comparative statics of endowment changes end up well behaved. ${ }^{6}$

\subsection{Garegnani}

Garegnani constructs a two-period two-good general equilibrium model that he suggests is as prone to capital-theoretic difficulties as aggregative models. The problem does not concern the existence of equilibria, but that plausible out-of-equilibrium behaviour will not lead markets to equilibrate when multiple capital goods are present. Specifically, in order for savings to come into equilibrium with investment, interest rates may have to rise when there is excess supply of savings and fall when there is excess demand.

\footnotetext{
6 The essay of Schefold's under discussion and Schefold (1997) argue that reswitching generates two additional paradoxes: (1) that adjustment mechanisms to reach equilibrium can be unstable, and (2) that the value of capital investment need not be inversely related to the interest rate. Point (1) is intriguing but not yet fully developed (see also footnote 8 below); point (2) is not a paradox from the general equilibrium point of view.
} 
In the first period of Garegnani's model, preexisting stocks of goods $a$ and $b$ are consumed or invested in second-period production. In the second period, labour and the investments from the previous period provide the inputs for activities producing new quantities of $a$ and $b$. Good $b$ is the numéraire in both periods. Garegnani models disequilibrium by fixing the interest rate at an arbitrary level and dropping the requirement that the first-period markets for $a$ and $b$ clear. How out-of-equilibrium consumption choices are made is left vague, but Garegnani argues that, with an additional condition on out-of-equilibrium demands for first-period goods, the economy's remaining endogenous variables (the prices and activity levels) are locally determined by the remaining equilibrium requirements (the market-clearing conditions for second-period outputs and labour and the zero-profit conditions for the two activities producing $a$ and $b$ ). ${ }^{7}$

Disequilibrium in Garegnani's theory is expressed in the savings-investment market. Savings is the value of the initial stocks of $a$ and $b$ less the value of the amounts of these goods consumed, and investment is as the value of $a$ and $b$ invested in second-period production; out of equilibrium, savings and investment may be unequal. Both savings and investment can be seen as functions of the interest rate alone, since Garegnani assumes that at any given interest rate the remaining endogenous variables (in particular the consumption levels in both periods) adjust to satisfy the remaining equilibrium conditions (excluding first-period market clearing). Excess demand and supply in the savings-investment market then leads the interest rate to rise or fall respectively. By a Walras's law argument, if savings does equal investment, then the markets for the stocks of both $a$ and $b$ in the first period clear and so full equilibrium is achieved.

Given that the quantity of $a$ and $b$ invested is determined by consumption demand for second-period output in Garegnani's adjustment scheme, investment as well as savings has a consumer demand component. Hence standard neoclassical arguments for why investment demand should be a well-behaved function of the interest rate do not apply. As the interest rate and hence other prices change, the effect on consump-

\footnotetext{
7 If agents can execute all desired trades out of equilibrium, no added condition on out-ofequilibrium demands is necessary. Having fixed the interest rate, the remaining endogenous variables consist of two activity levels and three relative prices (counting labour, there are five goods altogether) while the outstanding equilibrium conditions consist of the three remaining market-clearing equalities and two zero-profit equalities for the activities producing $a$ and $b$. Hence one would expect the five outstanding endogenous variables to be locally determinate. But Garegnani seems to intend agents' savings in disequilibrium to be constrained in such a way that the value of aggregate second-period excess demand equals zero, thus making one of the second-period market-clearing equalities redundant.
} 
tion demand by itself can lead investment and savings to respond counterintuitively and can ensure that a tâtonnement interest rate adjustment mechanism will not lead to equilibrium. Garegnani unfortunately does not follow Schefold in assuming that demand originates from a single agent, which might help to distinguish between consumer demand and the multiplicity of capital goods as a source of trouble. Possibly, the reswitching of techniques might by itself lead to a failure of tâtonnement adjustment, or magnify problems caused by multi-agent consumer demand, but it is hard to tell as the model stands. Garegnani's present paper is only an initial study, however, and in future work Garegnani promises to explore capital-theoretic issues in more detail.

But even if problems of capital aggregation sometimes lie behind the pathologies of out-of-equilibrium adjustment in Garegnani's model, the idiosyncrasies of the model will leave the significance of this finding cloudy. At least three markets should operate in the first period of a multiperiod model with two first-period goods: one market each for the two first-period goods and one or more borrowing-lending markets in which agents trade promises to deliver goods or nominal wealth in the future. But in Garegnani's model, only a savings-investment market functions, and here agents trade quantities of value-physical quantities of $a$ and $b$ multiplied by their prices - not quantities of goods. Garegnani asserts that the first-period markets for $a$ and $b$ for consumption purposes still clear. This is a hard claim to decipher since consumers and businesses purchase the same physical goods, but in any event excess demand or supply in the first period for $a$ and $b$ for investment purposes should lead to contemporaneous responses in the first-period prices of $a$ and $b$, not just in the interest rate.

The most common neoclassical understanding of out-of-equilibrium adjustment has prices in all markets responding simultaneously to non-zero excess demands according to a tâtonnement. Since strong stability results obtain when the consumer side of the model consists of a single agent, the multiplicity of capital goods would seem to be beside the point, being neither necessary nor sufficient for the stability of equilibrium. ${ }^{8}$ Possibly,

\footnotetext{
8 See Arrow et al. (1959), which considers exchange economies only. Stability in models of production faces the difficulty that producer demands and supplies are not well defined if technology is constant returns to scale. But when technology is decreasing returns to scale, the results in Arrow et al. (1959) may be extended. See also the Arrow and Hurwicz (1958a, 1958b)-Uzawa (1958) theory of gradient processes, which establish tâtonnement stability in pure production settings. Schefold (1997) voices doubt that stability will obtain in a singleagent production economy but does not examine an explicit model of simultaneous price adjustment in multiple markets.
} 
the multiplicity of capital goods could lessen the likelihood of stability when more than one agent is present. Garegnani rightly directs sharp criticism at the standard view that the excess demands that guide an out-ofequilibrium tâtonnement are the demands of price-taking consumers: when the economy is out of equilibrium, consumers will be constrained in what trades they can execute. Let me add that a simultaneous tâtonnement of all goods is particularly implausible when some goods appear only in the future. But Garegnani makes no progress by collapsing the entire adjustment process into a single savings-investment market.

\section{A SUGGESTION}

Schefold and Garegnani clarify that a convincing Sraffian critique of general equilibrium theory must focus on the stability and plausibility of equilibrium rather than existence. They pursue this project in different ways, Schefold by examining how equilibrium prices move through time when an economy's endowments change, Garegnani by studying the outof-equilibrium behaviour at a point in time. I have argued that neither strategy succeeds, at least not when the consumer demand side of the model is sufficiently well behaved.

Let me propose an alternative, which addresses the movement of prices through time and hence is closer in spirit to Schefold than to Garegnani. With no restrictions on preferences, equilibrium prices in an intertemporal economy can follow any path. But when the path of equilibrium prices is sufficiently convoluted, it is difficult to see how agents would be able to anticipate that path-as they must in a perfect foresight equilibrium where markets open sequentially. At least with regard to fulfilling agents' expectations, the long-run equilibria favoured by Sraffians are vastly more plausible.

But equilibrium price paths need not be arbitrary if factor prices are not set by supply and demand. Morishima in his famous turnpike theorem (1961) in effect showed that if all factors are sold at fixed prices and each production activity produces only a single output, then prices and interest rates necessarily converge through time. Morishima's theorem gives formal expression to the Sraffian thesis that the defects of neoclassical economics stem from the method of determining all prices by supply and demand and to the classical thesis that relative prices stabilize through time.

I do not mean to endorse a repeal of the law of supply and demand. Although labour is not bought and sold in auction markets, some factors

(C) Blackwell Publishers Ltd 2002 
are, and even labour markets respond to market pressure. Conversely, we still do not know what to make of the potential for complex competitive equilibrium price paths; just because they are possible does not mean they are likely. So perhaps there is no need for a substantial revision of competitive equilibrium theory.

Still, the Morishima turnpike theorem suggests that production economies can circumscribe the impact of arbitrary preferences on prices and hence exhibit more plausible equilibrium trajectories. A primary advantage of Sraffian theory is that it places production front and centre; this antidote to the neoclassical concentration on exchange may in the end prove more significant than the discovery of reswitching.

I have already applauded the Sraffian move from out-and-out rejection of the general equilibrium model to critical examination of the model's properties. But sizable neoclassical literatures can offer some leads. Specifically, studying how production can delimit the behaviour of equilibrium price paths may be more fruitful than hunting for a link between capital-theory paradoxes and the stability of out-of-equilibrium adjustment processes.

\section{REFERENCES}

Arrow K., Hurwicz L. (1958a): 'Gradient method for concave programming, I: Local results', in Arrow K., Hurwicz L., Uzawa H. (eds): Studies in Linear and Non-linear Programming, Stanford University Press, Stanford, CA.

Arrow K., Hurwicz L. (1958b): 'Gradient method for concave programming, III: Further results and applications to resource application', in Arrow K., Hurwicz L., Uzawa H. (eds): Studies in Linear and Non-linear Programming, Stanford University Press, Stanford, CA.

Arrow K., Block H., Hurwicz L. (1959): 'On the stability of competitive equilibrium II', Econometrica, 27, pp. 82-109.

Calvo G. (1978): 'On the indeterminacy of interest rates and wages with perfect foresight', Journal of Economic Theory, 19, pp. 321-37.

Gale D. (1973): 'A pure exchange equilibrium of dynamic economic models', Journal of Economic Theory, 6, pp. 12-36.

Garegnani P. (1976): 'On a change in the notion of equilibrium in recent work on value and distribution', in Brown M., Sato K., Zarembka P. (eds): Essays in Modern Capital Theory, Amsterdam, North-Holland.

Kehoe T. (1980): 'An index theorem for general equilibrium models with production', Econometrica, 48, pp. 1211-32.

Kehoe T., Levine D. (1984): 'Regularity in overlapping generations exchange economies', Journal of Mathematical Economics, 13, pp. 69-93.

Kehoe T., Levine D. (1985): 'Comparative statics and perfect foresight in infinite horizon economies', Econometrica, 53, pp. 433-53.

Kurz H. (ed.) (2000): Critical Essays on Piero Sraffa's Legacy in Economics, Cambridge University Press, Cambridge.

C) Blackwell Publishers Ltd 2002 
Mandler M. (1995): 'Sequential indeterminacy in production economies', Journal of Economic Theory, 66, pp. 406-36.

Mandler M. (1997): 'Sequential regularity in smooth production economies', Journal of Mathematical Economics, 27, pp. 487-504.

Mandler M. (1999a): Dilemmas in Economic Theory, Oxford University Press, New York.

Mandler M. (1999b): 'Sraffian indeterminacy in general equilibrium', Review of Economic Studies, 66, pp. 693-711.

Mas-Colell A. (1975): 'On the continuity of equilibrium prices in constant-returns production economies', Journal of Mathematical Economics, 2, pp. 21-33.

Mas-Colell A. (1985): The Theory of General Economic Equilibrium: a Differentiable Approach, Cambridge University Press, Cambridge.

Morishima M. (1961): 'Proof of a turnpike theorem: the "no joint production" case', Review of Economic Studies, 28, pp. 89-97.

Schefold B. (1997): Normal Prices, Technical Change, and Accumulation, Macmillan, London.

Sraffa P. (1960): Production of Commodities by means of Commodities, Cambridge University Press, Cambridge.

von Stackelberg H. (1933): 'Zwei kritische Bemerkungen zur Preistheories Gustav Cassel', Zeitschrift für Nationalökonomie, 4, pp. 456-72.

Uzawa H. (1958): 'Gradient method for concave programming, II: Global stability in the strictly concave case', in Arrow K., Hurwicz L., Uzawa H. (eds): Studies in Linear and Non-linear Programming, Stanford University Press, Stanford, CA.

Department of Economics

Royal Holloway College

University of London

Egham

Surrey, TW20 0EX

UK

E-mail:m.mandler@rhul.ac.uk

C) Blackwell Publishers Ltd 2002 